\title{
The experiences of early childhood development home visitors in the Eastern Cape province of South Africa
}

\begin{tabular}{|c|c|}
\hline \multicolumn{2}{|c|}{$\begin{array}{l}\text { Authors: } \\
\text { Lenette Azzi-Lessing }{ }^{1} \\
\text { Kim Schmidt }{ }^{2}\end{array}$} \\
\hline \multicolumn{2}{|c|}{$\begin{array}{l}\text { Affiliations: } \\
{ }^{1} \text { School of Social Work, } \\
\text { Boston University, Boston, } \\
\text { Massachusetts, United States }\end{array}$} \\
\hline \multicolumn{2}{|c|}{$\begin{array}{l}{ }^{2} \text { Department of Social Work } \\
\text { and Social Development, } \\
\text { Faculty of Social Sciences } \\
\text { and Humanities, University } \\
\text { of Fort Hare, East London, } \\
\text { South Africa }\end{array}$} \\
\hline \multicolumn{2}{|c|}{$\begin{array}{l}\text { Corresponding author: } \\
\text { Kim Schmidt, } \\
\text { kschmidt@ufh.ac.za }\end{array}$} \\
\hline \multicolumn{2}{|c|}{$\begin{array}{l}\text { Dates: } \\
\text { Received: } 04 \text { Mar. } 2019 \\
\text { Accepted: } 23 \text { July } 2019 \\
\text { Published: } 14 \text { Oct. } 2019\end{array}$} \\
\hline \multicolumn{2}{|c|}{$\begin{array}{l}\text { How to cite this article: } \\
\text { Azzi-Lessing, L. \& Schmidt, K., } \\
2019 \text {, 'The experiences of } \\
\text { early childhood development } \\
\text { home visitors in the Eastern } \\
\text { Cape province of } \\
\text { South Africa', South African } \\
\text { Journal of Childhood } \\
\text { Education 9(1), a748. https:// } \\
\text { doi.org/10.4102/sajce. } \\
\text { v9i1.748 }\end{array}$} \\
\hline \multicolumn{2}{|c|}{$\begin{array}{l}\text { Copyright: } \\
\text { (C) 2019. The Authors. } \\
\text { Licensee: AOSIS. This } \\
\text { is licensed under the } \\
\text { Creative Commons } \\
\text { Attribution License. }\end{array}$} \\
\hline \multicolumn{2}{|l|}{ Read online: } \\
\hline 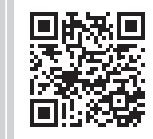 & $\begin{array}{l}\text { Scan this QR } \\
\text { code with your } \\
\text { smart phone or } \\
\text { mobile device } \\
\text { to read online. }\end{array}$ \\
\hline
\end{tabular}

Background: This article examines the development of early childhood development (ECD) home-visiting services in South Africa.

Aim: To examine the factors that could support the success of home-visiting programmes as well as to explore the experiences of bachelor's-level home visitors rendering such services.

Setting: This study was conducted in the Eastern Cape, a highly impoverished area of South Africa.

Methods: It begins with a discussion of the emergence of home-visiting as a strategy for the delivery of ECD services in South Africa and a review of the literature on ECD home-visiting, particularly with highly vulnerable, impoverished families. Next a focus group conducted with a small sample of home visitors as part of a multi-faceted community assessment is described. The results are examined within the context of challenges facing this particular part of South Africa and the nation as a whole.

Results: Four themes emerged as most prominent: (1) encountering the effects of extreme family poverty, (2) identifying high rates and multiple aspects of child maltreatment, (3) encountering scarce resources in high-need areas and (4) finding rewards and maintaining a desire to continue serving challenging populations.

Conclusion: This study provides a unique window on the challenges that ECD home visitors are likely to encounter when working with families living in extreme poverty, the resourcefulness that home visitors often demonstrate and the rewards to be found in this work.

Keywords: home-visiting programmes; early childhood development; social work; vulnerable young children; poverty.

\section{Introduction}

In recent years, around the globe, interest in early childhood development (ECD) and the variety of supports necessary for young children to develop optimally has expanded substantially and continues to grow (Britto, Engle \& Super 2013; Britto et al. 2017). In South Africa, the government has committed to ensuring that all young children and especially children in highly vulnerable families and communities are able to access a comprehensive package of quality ECD services by 2030 (Republic of South Africa 2015). This package will include programmes that support and reach out to children and their families at a household level through home-visiting programmes (Republic of South Africa 2015). It is thus significant to examine the factors that could support the success of home-visiting programmes as well as to explore the experiences of home visitors rendering such services.

As South Africa progresses in developing its system of ECD home-visiting programmes, understanding the challenges in providing these services and other experiences of home visitors is critical to developing effective programmes within this system. Although a number of studies have been conducted on the experiences of home visitors in other parts of the world (Burrell et al. 2009; Harden, Denmark \& Saul 2010), there is a dearth of information on the experiences of ECD home visitors in the African context and in South Africa in particular. This is problematic given that South Africa and many other African countries have extremely high levels of child poverty and the various risk factors and stressors typically present in impoverished families and communities. These nations also have less developed infrastructure and fewer resources to address these problems than in many other parts of the world. Because of this, home visitors in these countries are likely to face more extreme challenges in working with poor families with young children. These challenges are influenced, in both positive and undesirable ways, by the 
various geographic locations and cultural contexts in which home-visiting services are delivered.

This article examines the development of ECD home-visiting services in South Africa and the experiences of bachelorslevel home visitors in a highly impoverished area of the country. It begins with a discussion of the emergence of home-visiting as a strategy for the delivery of ECD services in South Africa and a brief overview of the ECD homevisiting field. A focus group conducted with a small sample of home visitors as part of a multi-faceted community assessment is described. The results are examined within the context of challenges facing this particular part of South Africa and the nation as a whole. Lastly, the limitations of this study and its contribution to the ECD home-visiting knowledge base are discussed, as are recommendations for future studies on the experiences of ECD home visitors in South Africa.

\section{Literature review}

\section{Emergence of early childhood development as a priority in South Africa}

Early childhood development was recognised as a matter of importance by the South African government as early as 1994 when the first democratic elections were held. Since then, legislation and policies such as the Convention on the Rights of the Child, various White Papers on Social Welfare and Education and the Children's Act 38 of 2005 have passed through parliament, all foregrounding the importance of ECD services (Atmore 2013). More recently, the 2030 Agenda on Sustainable Development was adopted by South Africa, the South African National Curriculum Framework (NCF) for children from birth to four, and the first National Integrated ECD (NIECD) Policy was approved by cabinet (Dhlamini 2016; Dlamini 2015). South Africa has aligned its National Development Plan (NDP) to the 2030 Agenda with the first six goals relating to the social development of people by addressing poverty, hunger, well-being, inclusive and quality education, gender equality, and access to clean water and sanitation. Investing in early childhood development has again emerged as a key priority for the South African government as essential to achieving the 2030 Agenda and the NDP, in particular the goals relating to people and social development (Motshekga 2015).

Within each of these six goals, targets relating to early childhood development can be seen with the time before birth and the first few years of life being noted as the most effective and cost-efficient time to intervene (Motshekga 2015). The NDP calls for quality ECD services that support the holistic development of children regardless of who the child is or where the child lives (National Planning Commission 2015). Both the NCF and the NIECD Policy are integral to the implementation of ECD services in South Africa as both provide the first framework since democracy, for the delivery of quality, equitable ECD services and programmes to all young children and their caregivers
(Republic of South Africa 2015). Even with South Africa's commitment to ECD, the majority of young children 'are still negatively impacted by a range of social and economic inequalities including inadequate access to healthcare, education, social services and nutrition' (Atmore 2013:152). Equitable and quality ECD services for all young children remain an ideal that South Africa has not yet achieved (Atmore 2013; Aubrey 2017).

\section{Challenges facing early childhood development in South Africa}

Ensuring optimal development for young children in South Africa remains a daunting task given the high rates of poverty and the challenges poverty brings. High rates of unemployment and inequality in wages continue to contribute to $55.5 \%$ ( $n=30.4$ million $)$ of South Africans living in poverty, with young children identified as one of the groups most vulnerable and likely to experience poverty (Aubrey 2017; Statistics South Africa 2017). Sixty-two per cent of children in South Africa under the age of 6 experience poverty, with $30 \%$ of these experiencing food poverty, making them vulnerable to hunger and malnourishment (Hall et al. 2017). This is extremely problematic given that undernutrition during the early years makes children vulnerable to future chronic diseases, poor educational performance, and behavioural and emotional problems (Victora et al. 2008). In addition to the poverty and malnutrition that some young children face, other risk factors such as low birth weight, infectious diseases, environmental toxins, high levels of stress, exposure to violence, maternal depression, disrupted caregiving and disabilities continue to affect far too many young children in South Africa (Republic of South Africa 2015).

More than a million children are born in South Africa every year, with many of these children living in rural areas, making access to ECD services problematic and costly to render (Hall et al. 2017). Other challenges facing ECD in South Africa include the poor infrastructure at ECD facilities where many community-based centres function without safe buildings or access to running water, electricity and sanitation. Government funding for ECD centres remains difficult to access, particularly for centres with inadequate infrastructure. Moreover, many ECD practitioners lack the educational qualifications and skills necessary to promote optimal development for the young children in their care (Atmore 2013).

\section{The importance of intervening early and effectively}

These challenges dramatically affect the learning outcomes for young children, given that a healthy and safe environment with nurturing caregivers at home and in well-resourced ECD programmes can stimulate learning and help prepare children for success in school and in life (Berry \& Malek 2017; Ebrahim, Seleti \& Dawes 2013). Conversely, when young children are exposed to the distress of living in poverty, unresponsive caregivers and/or a lack of environmental stimulation during their early years, their chances of 
repeating grades, developing special needs or dropping out of school are increased (Ebrahim et al. 2013; Reynolds 1998; Richter 1999, 2003). Such negative outcomes can have lifelong harmful implications (Anda et al. 2006; Cluver et al. 2015).

According to South Africa's NIECD Policy, the first 1000 days, starting from conception and continuing in the first 2 years after birth, offer 'a unique and invaluable window of opportunity to secure the optimal development of the child, and by extension, the positive developmental trajectory of a country' (Republic of South Africa 2015:16). The NCF supports early intervention as integral to ensuring the optimal development of children, stating that the future of the child, his or her community and society depends on early and effective intervention during these first 1000 days (Department of Basic Education 2015; UNICEF 2007). It follows then that for vulnerable families with risk factors that threaten the healthy development of their children, intervention should begin early with strategies that reduce the impact of these risk factors, as well as strategies that promote children's optimal development. Ideally, interventions should begin as soon as possible after conception, especially for these more vulnerable families.

\section{Home-visiting programmes as an early intervention strategy}

South Africa's NIECD Policy states that effective ECD services should be provided publically and should offer parenting support and capacity development through a variety of strategies. For the long-term provisioning of such strategies, the South African government has committed to the provisioning of a comprehensive, high-quality ECD programme that is offered across a range of settings such as the home, day mothers, non-centre-based programmes and ECD centres. To achieve this, the policy aims to introduce a number of new services. These services include home visits by community health workers to all vulnerable children aged from birth to 2 years; micronutrient and food supplementation for all pregnant women and young children; screening, counselling and referrals of all pregnant mothers and mothers of young children for mental health, substance abuse, domestic violence and of young children for child abuse or neglect; parenting support programmes, birth screening and follow-up to support the early identification of disabilities, and pre-registration during the third trimester of pregnancy for the child support grant (Republic of South Africa 2015). The successful implementation of these services will require a multidisciplinary programmatic approach that will include all of the relevant stakeholders, with a particular commitment to identifying and serving vulnerable children (Republic of South Africa 2015).

Home-visiting programmes represent one important strategy for addressing the needs of young children at risk for poor developmental outcomes (Ebrahim et al. 2013). Home visits allow for ECD programmes to be offered to families and children within the context of their own communities and homes, providing a unique opportunity for the worker and family to partner in the rendering of prevention and early intervention services. The utilisation of home-visiting programmes to serve vulnerable young children and their families has gained popularity around the world because of the following perceived benefits:

- Providing services to families in their homes helps to overcome barriers to participating in services, especially the lack of transportation (Collins, Jordan \& Coleman 2010).

- The home environment is often an ideal setting for assessing the strengths and needs of families as it provides a complete picture of their lives than can be seen in an office setting (Collins et al. 2010).

- Visiting families in their homes may facilitate trusting and productive relationships between home visitors and family members. This may, in turn, improve the chances for services to be successful (Miedel \& Reynolds 1999).

- Home visits can be helpful in increasing parental involvement in the early childhood care and education of their children (Miedel \& Reynolds 1999).

Most of the well-known models of ECD home visiting require the scheduling of visits on a regular basis, ranging from one visit per week to monthly. These programmes typically utilise a curriculum to promote parents' understanding of their children's early development and encourage parents in their role as their child's first teacher. Many programmes also educate parents regarding ways to ensure the health and safety of their children and work to link families with additional resources in their communities (Gomby, Culross \& Behrman 1999). Examples of formal home-visiting programmes developed in South Africa include the Family Literacy Project in KwaZulu-Natal, the Family and Community Motivators programme developed by the Early Learning Resource Unit in Cape Town, the Family in Focus Programme developed by the Foundation for Community Work in Cape Town, the Parent-Infant Intervention Home Visiting Programme also in Cape Town and the Integrated ECD Community Development Programme in the Eastern Cape (Ebrahim et al. 2013; Gwele \& Ebrahim 2019; Van Niekerk, Ashley-Cooper \& Atmore 2017).

The literature suggests that three aspects of home-visiting programmes are critical to programme success (AzziLessing 2013). The first aspect relates to family engagement, which refers to the quality of the relationship that the child and family have with the home visitor. Several studies show that the quality of engagement affects the families' level of participation in home-visiting services and the effectiveness of these services (Roggman et al. 2008; Wagner et al. 2003). Home visitors should be skilled in building relationships with families that are based on values such as respect, self-determination and confidentiality. Moreover, they should have the capacity to identify strengths in even the most challenging family situation (Grobler, Schenk \& Mbedzi 2013).

The characteristics, training and support of home visitors form the second aspect critical to the effectiveness of a 
home-visiting programme. Certain personal characteristics of the home visitor such as age, language, race or experience seem to affect the ability of home visitors to engage with the family and could impact the success of their work (Harden et al. 2010). For instance, families may be more comfortable with a home visitor who shares their cultural background and is able to communicate easily in their primary language. Another important set of characteristics is the skills and expertise of the home visitor. Home visitors should be adequately trained, as families want and need a home visitor who is knowledgeable and able to support them with the challenges they face (Wagner et al. 2003). Moreover, ongoing support by experienced supervisors is essential for home visitors to work effectively with families. As discussed later in this article, adequate education, training and support are especially important when working with highly vulnerable families (Azzi-Lessing 2013, 2017).

The third critical aspect of ECD home-visiting programmes is their capacity to effectively match the services they deliver to the unique set of wants and needs that each family presents. Families are more likely to engage well when services are responsive to their expectations and needs, and both responsiveness and engagement affect programme success. Home visitors must be skilled in eliciting from families their needs and expectations, as well as in negotiating and establishing goals with the family. Homevisiting programmes must have the capacity to respond to families' identified needs, while at the same time ensuring that factors that threaten the well-being and optimal development of the children are reduced (Azzi-Lessing 2011). Having an adequate array of services, such as adult and child health and mental health services, to which families can be linked, available in the local community is essential to addressing the multiple needs many vulnerable families experience (Azzi-Lessing 2011, 2013, 2017; Schorr, Farrow \& Sparrow 2014).

\section{Home-visiting services in the South African context}

Home-visiting programmes as an important option for advancing ECD services are beginning to receive attention in South Africa, despite the lack of significant government funding to support widespread implementation (Gwele \& Ebrahim 2019). One study conducted in the Western Cape identified positive outcomes for home-based parenting programmes in improving early mother-infant interactions and attachment in families (Cooper et al. 2009). Another study in the Western Cape showed that a home-based support programme was helpful in supporting vulnerable families in the recovery of children suffering from malnourishment (Le Roux et al. 2010). In South Africa, home visits are done by both paraprofessionals, including trained community members, auxiliary social workers and community health workers, as well as by professionals such as social workers or nurses. In the above-mentioned studies, well-respected community members, who were known to have good parenting skills, were trained as paraprofessionals to support vulnerable families with young children in their communities (Cooper et al. 2009; Le Roux et al. 2010). These studies suggest that using paraprofessionals for homevisiting programmes may have advantages. However, for children and families experiencing a complex array of risk factors, professionals with specialised education, such as social workers, may be better equipped to deliver homevisiting services (Azzi-Lessing 2013).

\section{Theoretical framework}

This study has utilised an ecological theoretical framework that recognises that human development is interactional in nature and that children develop in the context of families and families develop in the context of the communities in which they live (Bronfenbrenner 1994). Using the ecological theory, it can be understood that where risk factors exist within the family or community, the young child's development may be threatened as the young child develops within these contexts. The opposite may also then be true that where young children and their families are empowered to have strong relationships with community ECD services, their development can be supported and ECD services begin to act as a protective factor for the young child who is exposed to risk factors within the family or the community. Risk factors that may exist within the family include high rates of unemployment, poverty, family violence, substance abuse or disrupted caregiving (Schmidt et al. n.d). These same risk factors may exist within other families in the community effecting the functioning of the community as a whole. Using the ecological systems perspective suggests that young children can be supported in the families and communities where they reside to develop resilience to the adverse conditions that may exist around them. Community-based ECD services, offered through centre- or non-centre-based programmes, have been recognised internationally as being one of the most effective ways of supporting the optimal development of the young child, especially where the child is exposed to risk factors within the family or community. In the same way that the young child's development is influenced by the context in which they live, the experiences of the home visitors who were interviewed as a part of this study will have been influenced by the context of the families and communities within which these home visits were conducted. The experiences and observations of the home visitors and the setting and context within which the study took place will be described in more detail below.

\section{Experiences and observations of home visitors \\ Setting}

This study, a focus group of home visitors working with families of children enrolled in ECD centres, took place in the Buffalo City Metropolitan Municipality in the Eastern Cape Province of South Africa. The Eastern Cape is a large rural province with 7 million people, constituting $12.6 \%$ of the nation's population (Statistics South Africa 2016). The province is characterised by extreme levels of poverty, 
including the nation's highest child poverty rate, and high rates of unemployment (Statistics South Africa 2016). Seventy-nine percent of young children live below the poverty line, making them vulnerable to hunger, malnutrition and food insecurity (Atmore 2013; Hall et al. 2017). Poverty rates are considerably higher in the Eastern Cape than for South Africa as a whole, placing young children in this province at particularly high risk of poor outcomes. For instance, malnutrition is the third largest cause of death for children under 5 years in the Eastern Cape (Massyn et al. 2016).

Such extreme poverty is often accompanied by high rates of family violence, substance abuse and mental health challenges, with the capacity of parents to provide adequate care for young children being compromised by these adverse conditions (Cooper et al. 2011). The Eastern Cape has the highest rates of women abuse (32\%) in South Africa and it spends the third largest amount per province on child care and protection caused by childhood exposure to family violence (Fang et al. 2017; Statistics South Africa 2017). These statistics are alarming, as the adverse consequences of childhood exposure to such risk factors are often severe and can lead to lifelong deficits in learning, as well as to chronic mental and physical health problems (Azzi-Lessing 2017; Cooper et al. 2011).

\section{Context}

The present study was a component of a larger community assessment of existing capacity for providing ECD services in the Buffalo City Municipality area of the Eastern Cape. The community assessment was developed and implemented through a transdisciplinary partnership led by faculty and administrators at the East London branch of the University of Fort Hare (UFH), aimed towards building capacity for the delivery of high-quality ECD services in the surrounding area. This branch of UFH plays a central role in the education of the area's teachers, social workers and healthcare providers. The partnership was developed to support UFH's efforts to create degree programmes in ECD and infuse expertise in ECD and family support into teaching and learning across a wide variety of schools and disciplines at the university, as well as in surrounding community-based organisations (CBOs) that support ECD service providers. To accomplish this, UFH established partnerships with a number of local CBOs, as well as with Wheelock College ${ }^{1}$ in the United States, a long-established leader in educating ECD professionals globally.

The community assessment was overseen by transdisciplinary steering and research groups, which were charged with guiding various facets of the partnership's work. As Weigel and Martin (2006) point out, a community assessment can be an effective tool for identifying local needs and resources and to learn about the experiences of ECD service providers. The results can help ensure that new resources are customised to meet the unique needs and build on the existing resources in a given community (Finifter et al. 2005; Moshabela, Sips \& Barten 2015). The goal of this community assessment was to augment available demographics and other quantitative data with in-depth, qualitative information regarding needs, gaps and resources available to support and promote high-quality ECD services in the Buffalo City Municipality area.

The community assessment was embedded in a social constructivist interpretivist theoretical framework that recognises that individuals' experiences are socially constructed (Lipshitz 2012, cited in Mouton \& Marais 1994; Vorster et al. 2016) and sought to examine the context in which ECD service providers work, and their experiences within that context. There were three components to the community assessment (1) semi-structured individual interviews with teachers and principals in 10 local ECD centres, (2) semi-structured interviews with leaders of CBOs that provide training and support to ECD service providers and (3) the present study, a focus group conducted with eight home visitors working with families of children attending ECD centres.

\section{Study population and sampling strategy}

Non-probability purposive sampling was used in the selection of eight home visitors who participated in the focus group. Non-probability sampling is useful in situations such as the community assessment described here, where time and funding are limited and randomisation is not feasible. Purposive sampling refers to choosing subjects based on their characteristics (Etikan, Musa \& Alkassim 2016). In this case, the subjects were chosen because of their roles in providing home visits to young children and their families. All of the home visitors were employed by the same CBO in the Buffalo City area to provide home visits and a broad range of services to families of children attending any one of the ECD centres with whom the CBO had a relationship. This included ECD centres in a township and in a nearby rural area, all of which served primarily impoverished families. Unlike the well-known models of home-visiting (Azzi-Lessing 2011; Ebrahim et al. 2013), the type of home visiting provided was informal, without a specific curriculum or primary area of focus, that is, child development, parentchild relationships, child health and so on. Instead, the home visitors addressed whatever needs were identified by the families they served, and in some situations, needs that the home visitor identified, such as improper supervision of a young child. The programme was also informal in that there was no set number of cases each home visitor carried; rather each was encouraged to select families with the greatest or most urgent needs from among the families referred to them by the ECD centres. Families with the most acute needs were seen more frequently than those who were not in crisis and/ or had fewer needs.

All of the home visitors had recently earned bachelor's degrees in social work and were nearing the middle of a 
1-year paid internship at the CBO. The sample consisted of seven females and one male and all were in their 20s except for one who was in her early 30s. The mean age was 25 . Only one of the home visitors had previous employment experience; however, all but two had personal child-caring responsibilities. Five had children of their own and one was caring for her four cousins on the weekends.

\section{Data collection}

A focus group format was used to conduct a semi-structured interview of the eight ECD home visitors. This method enabled a broad exploration of the home visitors' experiences and perspectives within the constraints of limited time (on the part of the researchers and the home visitors) and funding. It also provided an opportunity for the home visitors to respond to one another's comments as they reflected on their experiences, a process that increased the productivity of the discussion (Krueger \& Casey 2014). To make participation in the 2-hours session as convenient as possible, the focus group was conducted in a private conference room at the $\mathrm{CBO}$ where the home visitors were employed. No other staff from the CBO were present when the focus group was conducted.

The semi-structured interview format used to prompt discussion in the focus group consisted of 19 questions that addressed three categories of inquiry: (1) ECD home visitors' experiences in providing services to families with young children, (2) the training and support available to the home visitors and (3) their reactions to and feelings regarding the work they were doing. As the focus group progressed, several of the 19 prepared questions were combined and not all of the questions were addressed because of time constraints and the multi-faceted discussions that some of the questions provoked. Examples of the questions asked in the focus group include the following: on what areas of concern do you most commonly work with parents? What aspects of your work do you find most challenging? What additional resources would make your work more manageable and/or more effective? Participants were also asked to discuss aspects of their work that they found most rewarding and their future career plans. Two members of the community assessment team facilitated the discussion and took notes, while a third member took more detailed notes.

\section{Data analysis}

The focus group facilitators and the note-taker met after the focus group had concluded to compare and integrate notes and ensure that participants' responses were accurately recorded and summarised. The discussion was analysed using thematic content analysis, which entailed identifying prevalent themes from the transcribed notes of the discussion. Thematic analysis is recognised as a valuable qualitative research tool that can 'potentially provide a rich and detailed, yet complex account of data' (Braun \& Clarke 2006:5) and is commonly used to analyse the results of focus groups.

\section{Ethical considerations}

Ethical clearance for the study was obtained from Wheelock College. Informed consent was obtained from the communitybased organisation that employed the home visitors and from each member of the sample. The home visitors were informed that their participation was entirely voluntary and that they could refuse to participate in the focus group, withdraw from participating at any time and/or refuse to respond to any of the questions or prompts without any penalty. They were also informed that their responses would be kept confidential and that their anonymity would be protected in reports and publications that utilised focus group findings. Prior to their participation, sample members were asked to sign a consent form that detailed these protections.

\section{Findings and discussion}

A wide range of topics surfaced during the focus group, as participants seemed eager to share their experiences and observations. Four themes emerged as most prominent in the discussion: (1) encountering the effects of extreme family poverty, (2) identifying high rates and multiple aspects of child maltreatment, (3) encountering scarce resources in high-need areas and (4) finding rewards and maintaining a desire to continue serving challenging populations.

\section{Theme 1: Encountering the effects of extreme family poverty}

Unsurprisingly, given the impoverished communities in which the home visitors worked, they all identified families having insufficient resources to meet their basic needs and to keep their children healthy and safe, as a major challenge. Several noted that a lack of employment opportunities as well as the inadequacy of the child support grant provided by the government to poor families caused hardships for many families. Moreover, several of the home visitors observed that many of the families were further impoverished because their children's fathers deny paternity to avoid paying child support, absent parents collect and spend the grant, while the grandparents caring for their children do not have access to these funds, and loan sharks frequently prey upon poor families, making their financial situations even worse. Feedback by several of the participants were:

'A lot of times the mother keeps the grant and spends it on herself while the granny is the one taking care of the children and she gets nothing.'

'Loan sharks get a lot of the grant cards because parents can't repay them.'

'We are seen as troublemakers sometimes when we try to get the grant to go to the one caring for the children.'

The home visitors described ways in which a lack of financial resources is a barrier for families in obtaining critical services. Several reported that many families fail to obtain the healthcare and mental health services they need because they are unable to pay the fees attached to these services. One home visitor noted that local hospitals had very long waiting 
lists for treating children with disabilities, and that families were required to pay for these services when delivered by a CBO. All of the home visitors observed that such barriers, along with struggles to afford adequate food, housing and other basic resources, contributed to high levels of stress in the families they served.

These observations are not surprising given the high rates of child poverty in South Africa and particularly in the Eastern Cape. The implications of hunger and malnutrition on development during early childhood are widely known and can have long lasting and serious consequences on the child's ability to develop optimally (Atmore 2013; Victora et al. 2008). A substantial body of research suggests that if the foetus, infant and young child do not receive adequate nurturement and good quality care, the child's potential for reaching full cognitive, emotional, social and physical development may be jeopardised (Centre on the Developing Child 2007; Mulder et al. 2002; Phillips \& Shonkoff 2000; Richter 1999, 2003; Shonkoff \& Garner 2012; Victora et al. 2008). One study estimates that there are more than 200 million children in low- and middle-income countries who do not reach their full cognitive potential because of povertyrelated malnutrition and inadequate care during early childhood (Grantham-McGregor et al. 2007 in Petersen et al. 2010). Without effective intervention, children growing up in highly stressful, impoverished families such as those described by the home visitors are at a high risk for poor long-term outcomes, including school failure, criminal behaviour, and lifelong mental and physical health problems (Anda et al. 2006; Cluver et al. 2015).

\section{Theme 2: Identifying high rates and multiple aspects of child maltreatment}

All of the home visitors identified various aspects of child maltreatment as their greatest concern by far, as they frequently encountered instances of child neglect, as well as physical and sexual abuse, in the families they served. They all agreed that it was the most challenging aspect of their work. Child neglect was reported to be very common, especially among families with young teen parents, whom they described as often being too immature to care for their children. The home visitors noted that grandparents often step in to care for their grandchildren in these situations. The home visitors also described several instances in which young children were left alone to roam the streets because no family members were willing or able to care for them. They noted that these unsupervised children were left vulnerable to sexual assault and other harms perpetrated by neighbours or strangers.

Neglect also occurred when mothers rejected and failed to care for their infants or young children because the child was identified as having a disability or HIV/AIDS (human immunodeficiency virus, acquired immunodeficiency syndrome), two conditions that continue to carry a high level of stigma in many communities in South Africa. Several of the home visitors noted that they also commonly saw parents impaired by addiction to drugs and/or alcohol who were failing to meet their children's needs. Several reported instances in which the neglect was worsened when an addicted parent would leave children unattended while engaging in prostitution to earn money to buy drugs and/or alcohol:

'Some of the mothers reject the child; they are ashamed if the child has HIV or is slow.

'They [parents] know if they put the child [with a disability] in an institution they won't get the grant so they just leave the child home alone'.

All of the home visitors reported that they also frequently learned of incidents of physical and sexual abuse of children within the children's own families. Several noted that harsh discipline was used in many of the families they visited. Several of the home visitors reported situations in which mothers failed to report to authorities a child's father or the mother's boyfriend physically or sexually abusing the child. They identified the stigma surrounding sexual abuse as one of the reasons for this failure to report abuse or seek medical attention for the child; another reason was that the mother and her children were often financially dependent upon the abusive father or boyfriend:

'Parents beat their children because they were beaten as children.'

'There is lots of abuse; parents treat their children the way they were treated.'

'Sexual abuse is very common.'

'They [mothers] won't report the abuse if it's the breadwinner doing it.'

The home visitors' observations reflect findings of numerous studies, suggesting a strong link between poverty and child maltreatment (Coulton et al. 1995; Slack et al. 2004). They also reflect the very high rate of child maltreatment in South Africa and in the Eastern Cape in particular. In South Africa, homicide rates for children under 5 years are more than double those in other low- and middle-income countries (Mathews et al. 2012 in Morgan 2013). Thirty-three per cent of parents in South Africa continue to use severe corporal punishment in the home, with children under the age of 5 being most likely to be beaten within the home (Dawes, Kropiwnicki \& Richter 2005; UNICEF 2011, in Martin 2015). Children in South Africa also face high levels of sexual violence, with over 20000 cases being reported in 2011 and 2012, and children in the rural areas such as the Eastern Cape being at even higher risk (Martin 2015). Although current statistics reveal very high levels of such violence, the full extent of the problem is unknown because of under-reporting (Martin 2015; Richter and Dawes in Morgan 2013). It is well documented, however, that violence and other forms of maltreatment can impede children's chances of developing normally and succeeding in school and in life (Mathews \& Gould 2017).

Additional challenges inherent in this work include gaining access to the family's home in situations where resistant 
family members may prefer not to engage with the home visitor or where they may react aggressively and pose a physical threat (Dwyer 2012; Garthwait 2008; Pope \& Hadden 2011). The physical environment within the home might also make confidentiality difficult to manage (Pope \& Hadden 2011) as the South African context of housing often involves an informal structure with a large extended family and neighbours close by. These and other complexities further support the need for well-trained professionals, to be placed in the role as home visitors within ECD programmes serving impoverished, highly vulnerable families.

\section{Theme 3: Encountering scarce resources in high-need areas}

The first two themes demonstrate that the home visitors participating in the focus group were serving families with multiple complex needs that threatened the healthy development and future school success of the young children in these families. A shortage of various types of resources make the home visitors' attempts to address these extreme needs even more daunting than they already would be. The problem of inadequate resources also applies to the limited tools available for the home visitors to perform their work. They reported that they had to use their own laptops for keeping records on their work because the $\mathrm{CBO}$ that employed them was unable to provide computers. The CBO was also unable to provide cars or drivers, so the home visitors relied on taxis and reported that taxi schedules limited when they could visit families on their caseloads. They also lacked materials for teaching parents about early child development, learning and care.

All of the home visitors described how shortages of various other services hampered their ability to assist the families they served. They reported long waiting lists for obtaining adult and child mental health services as well as for services for children with disabilities. A few expressed their concerns that extreme delays in obtaining these services meant that mental health problems and disabilities would worsen and that crucial windows of time for addressing these problems were being missed. All of the home visitors identified inadequate resources for addressing child maltreatment, citing long delays in responses to reports of child abuse and neglect and in following-up on confirmed cases because of child protective staffing shortages and insufficient transportation available to child protective workers. They cited also a shortage of foster homes available for children who could not be safely cared for by their families. Some of the home visitors expressed a wish that these crucial child protective services could be developed and provided by the $\mathrm{CBO}$ at which they were employed. All expressed a desire that their $\mathrm{CBO}$ could employ its own professionals from an array of disciplines to address the severe shortage of resources in the communities in which they worked:

'There are long waiting lists for services at the hospitals.'

'The CBOs have waiting lists, too and families have to pay a fee for those services.'
'I wish [the CBO that employed the home visitors] had their own psychologists, nurses, speech therapists and other specialists.'

'We should have our own nurses to examine children and give them their immunisations so that our families don't have to wait so long.'

The experiences of these ECD home visitors reflect the extreme lack of resources to address the needs of vulnerable families in the Eastern Cape and other parts of the country (Govender 2015; Leeuw 2017; Schmidt \& Rautenbach 2016). Many of the country's CBOs and government agencies are experiencing severe funding challenges impacting the availability of staff and resources, such as vehicles, to provide home visits and other services to these families (Narsee 2013). This is further complicated by the sometimes very large and rural areas in which home visits are conducted. These challenges affect not only the provision of ECD home visits but also the response to reported cases of vulnerable children and their families who are in desperate need of additional professional support and intervention.

\section{Theme 4: Finding rewards and maintaining a desire to continue serving challenging populations}

Despite the multiple and extreme challenges they encountered, all of the ECD home visitors indicated that they found their work rewarding and worthwhile, particularly their intervention with parents and their efforts towards community development. They found gratification in providing information and education to parents regarding their children's development and well-being, as well as in linking families to whatever resources were available in the community. The home visitors reported that they used an empowerment approach, consistent with their social work education, in mentoring parents and helping them to develop skills. They also reported being gratified when they were able to observe the results of their work with parents, most often in the form of parents demonstrating more effective parenting skills:

'We guide the parents rather than doing for them.'

'We empower parents by linking them to the resources they need.'

'It's rewarding when you see parents doing the things you taught them to do with their children.'

The second area in which the home visitors found gratification was in their work together and with service providers from other organisations towards improving and expanding the array of resources for vulnerable families within the communities they served. They described how they worked together to organise workshops for parents to come together and learn about their children's development and ways to support optimal development, early learning and well-being for their children. These workshops also provide opportunities for parents and service providers to share information regarding other resources available in the community. The home visitors 
noted that bringing parents and service providers together for such purposes was especially important in the rural areas they served, where families typically lived farther away from one another and from the resources they needed. They reported finding fulfilment in developing relationships with staff members from other organisations as well as with tribal leaders in working to change communities for the better:

'We work together to provide things like parent training when those things are missing in the community'.

'We have workshops [held in community centres] that we create so parents can get information in one place'.

'It's exciting to be seen as a change agent'.

'We liaise with staff from other CBOs to help meet families' needs and getting to know other service providers is enjoyable'.

All the ECD home visitors expressed a desire to continue working in their current roles. However, their employment at the $\mathrm{CBO}$ was considered a paid internship and would last for only 1 year. Participants explained that there are few, if any jobs in the local area for social workers at the bachelor's level, even though the South African government offers bursaries for students to major in social work. All indicated that they would need to find work in retail, food service or other lowskilled position to support themselves after their internships ended. All intended to apply for master's programmes once they were able to afford it, as they saw a postgraduate degree as necessary for pursuing their career goals.

All but one of the home visitors planned to continue pursuing a career in human services, although none planned to continue in the ECD field. Two participants were planning to work together to open an NGO that would include a children's home after obtaining their master's degree in child welfare, one aspired to work as a social worker with prisoners and another expressed an interest in becoming a probation officer, psychologist or agriculture worker. One of the home visitors planned to work with children, but was uncertain of the type of position she would pursue, and another aspired to become a marriage counsellor. Another planned to remain in human services, but had not decided upon a specific area of practice. The only participant not planning to work in human services intended to work in some aspect of gardening through the Department of Agriculture.

The links between variables that include clients' characteristics, workers' stress levels, workplace environment, and workers' job satisfaction and commitment to their profession have been studied for both home visitors and social workers (Acker 2004; Burrell et al. 2009; Hombrados-Mendieta \& Cosano-Rivas 2013). There is increasing evidence that home visitors working with impoverished families affected by multiple stressors are at risk of experiencing secondary trauma and burnout (Ebrahim et al. 2011; Harden et al. 2010; Gill et al. 2007). It is therefore notable that the home visitors participating in the focus group did not raise the topics of burnout or secondary trauma, nor did any of them indicate that they view their jobs in negative terms. When asked about stress, some of the home visitors mentioned feeling occasional stress from 'dealing with hard cases' and sometimes having to 'do the work of other providers' when their colleagues from other CBOs failed to follow through. When asked about self-care, several of the home visitors referred to their religious practice and/or support from friends and family members:

'Church is where I get counselling.'

'I like to listen to South African Gospel music at home.'

'I talk to my mother who is an ECD practitioner.'

All of the participants indicated that they received adequate supervision and support from the CBO that employed them. These home visitors also apparently had strong bonds and effective working relationships among themselves and with staff from other NGOs, which along with their apparent resourcefulness enabled them to compensate somewhat for the dearth of resources in the communities they served. Other studies suggest that adequate levels of support in the workplace, including that from supervisors and co-workers, help to alleviate the effects of secondary trauma and may help to prevent burnout among home visitors working with highly vulnerable families (Burrell et al. 2009; Harden et al. 2010; Gill et al. 2007; Lee et al. 2013). This may help account for the participants finding their work, however challenging, to be worthwhile and rewarding and for their desire to remain in the human services field. The positive attitudes of the home visitors may also be attributable, in part, to the short amount of time (approximately 6 months) in which they had been working in the programme. Another factor that should be considered is that these home visitors had social work degrees and saw themselves as professionals with the skills and expertise necessary to be successful in their work. A lack of this sense of professionalism and competence may play a role in the amount of stress home visitors experience in their roles (Ebrahim et al. 2011; Gwele \& Ebrahim 2019).

\section{Limitations and contributions of this study}

Generalisation of the results of the current study is limited by several factors, including the very small sample size, the fact that all the participants were employed by the same $\mathrm{CBO}$ and the brevity ( 2 hours) of the focus group. Moreover, this study took place in a single geographic area. The experiences of ECD home visitors in other parts of South Africa are likely to differ somewhat, reflecting variations in the resources and challenges in the communities in which they work. The fact that the home visitors used an informal approach in working with families rather than a specific curriculum or with a specific focus, that is, child health and/or parent training, limits the generalisability of the results to more formal models of home-visiting. Another limitation is that the participants in the present study were all bachelor's-level social workers, and as previously stated, the ECD home- 
visiting workforce in South Africa includes a wide range of providers with various levels of education and expertise. These factors would undoubtedly influence home visitors' day-to-day experiences working with families. Lastly, given that participants in the focus group had been employed as home visitors for approximately 6 months, their responses do not reflect those of more seasoned workers, who may have acquired more skills and/or be more at risk of burnout.

Despite these limitations, this study provides a unique window on the challenges that ECD home visitors are likely to encounter when working with families living in extreme poverty, the resourcefulness that home visitors often demonstrate, such as in creating workshops and parenttraining groups, and the rewards to be found in this work. In addition, it illuminates the multiple ways in which such poverty threatens to harm the well-being and life chances of young children. The study also documents the extreme difficulties poor families encounter in obtaining resources and services to meet their needs.

Moreover, findings from the focus group reflect research documenting a strong link between family poverty and child maltreatment and the importance of home visitors having the skills necessary to identify and address child maltreatment and a range of other daunting challenges, including substance abuse in the families they serve. The findings suggest that ECD home visitors serving impoverished families should have adequate education and supervisory oversight and support. Lastly, the findings show how home-visiting services alone are insufficient to address the needs of extremely poor families and they highlight the importance of the availability of an array of relevant resources and services within impoverished communities.

\section{Recommendations for future research}

Additional research examining the experiences of ECD home visitors working with highly vulnerable families of young children in South Africa is warranted, given the scarcity of available information regarding this aspect of the ECD service delivery system. Studies with larger samples of home visitors working with families at various levels of risk, employed by a variety of organisations, and in differing geographic locations would expand the knowledge base beyond the limitations of the present study.

Inclusion of home visitors with differing levels of experience and education would be particularly helpful in understanding the role of these variables in how home visitors approach their work, and their capacity to manage secondary trauma and other factors that lead to burn out. Examining which levels of education and experience best prepare home visitors for working with families at various degrees of vulnerability and risk would be especially valuable at this point in time, as South Africa progresses in building its ECD service delivery system. This aspect of home visiting has not been well studied in other parts of the world, and ensuring a good fit between families' needs and home visitors' skill levels is especially critical to the design of the system in South Africa and other nations where there are very limited financial resources available for home-visiting and other ECD programmes.

Additional research on the well-being and morale of ECD home visitors in the South African context is also needed. There are a number of relevant studies that have been conducted in other parts of the world; however, most of these studies focus on home visitors serving less poor families with challenges that are far less daunting than those experienced by the most vulnerable families in South Africa and other nations with very high levels of child poverty (Azzi-Lessing 2013). The harsh conditions under which the latter families live and the extremely traumatic experiences of children and other members of these families place the home visitors who serve them at high risk of secondary trauma, high levels of stress and burnout, and departure from this work (Ebrahim et al. 2011; Gwele \& Ebrahim 2019). Future studies examining the personal characteristics of ECD home visitors, the stressors and supports in their personal lives and workplaces, and how these factors contribute to and/or mitigate burnout and departure from this work would provide information necessary to the development of critical systems of support for those who take on this challenging but very important work.

\section{Acknowledgements}

The authors would like to specially acknowledge the University of Fort Hare (UFH) Early Childhood Development Centre of Excellence - Dr Namhla Sotuku (Director), Mr Sive Makeleni and the late Mrs Nokulunga Sali, Wheelock CollegeDr Azzi-Lessing, South Africa Partners, Loaves and Fishes, the ELMA Philanthropies and the Govan Mbeki Development and Research Centre at the University of Fort Hare.

\section{Competing interests}

The authors declare that they have no financial or personal relationships that may have inappropriately influenced them in writing this article.

\section{Authors' contributions}

L.A.-L. developed the research proposal and collected the data. Together the authors wrote the findings and developed the research article.

\section{Funding information}

Funding for this study was obtained from the ELMA Philanthropies.

\section{Data availability statement}

Data sharing is not applicable to this article as no new data were created or analysed in this study. 


\section{Disclaimer}

The views and opinions expressed in this article are the authors' own and not an official position of the institutions or funders.

\section{References}

Acker, G.M., 2004, 'The effect of organizational conditions (role conflict, role ambiguity, opportunities for professional development, and social support) on job satisfaction and intention to leave among social workers in mental health care', Community Mental Health Journal 40(1), 65-73. https://doi.org/10.1023/ B:COMH.0000015218.12111.26

Anda, R.F., Felitti, V.J., Bremner, J.D., Walker, J.D., Whitfield, C.H., Perry, B.D. et al., 2006, "The enduring effects of abuse and related adverse experiences in childhood', European Archives of Psychiatry and Clinical Neuroscience 256(3) 174-186. https://doi.org/10.1007/s00406-005-0624-4

Atmore, E., 2013, 'Early childhood development in South Africa-progress since the end of apartheid', International Journal of Early Years Education 21(2-3) 152-162. https://doi.org/10.1080/09669760.2013.832941

Aubrey, C., 2017, 'Sources of inequality in South African early child development services', South African Journal of Childhood Education 7(1), 1-9. https://doi. services', South African Journ
org/10.4102/sajce.v7i1.450

Azzi-Lessing, L., 2011, 'Home visitation programs: Critical issues and future directions' Early Childhood Research Quarterly 26(4), 387-398. https://doi.org/10.1016/j. ecresq.2011.03.005

Azzi-Lessing, L., 2013, 'Serving highly vulnerable families in home-visitation programs', Infant Mental Health Journal 34(5), 376-390. https://doi.org/10.1002/imhj.21399

Azzi-Lessing, L., 2017, Behind from the start: How America's war on the poor is harming our most vulnerable children, Oxford University Press, New York.

Berry, L. \& Malek, E., 2017, Caring for children: Relationships matter. South African Child Guage, Children's Institute, University of Cape Town.

Braun, V. \& Clarke, V., 2006, 'Using thematic analysis in psychology', Qualitative Research in Psychology 3(2), 77-101. ISSN 1478-0887, viewed 20 June 2017, from hesearch in Psychology 3(2), 77-leprints.uwe.ac.uk/11735.

Britto, P.R., Engle, P.L. \& Super, C.M. (eds.), 2013, Handbook of early childhood development research and its impact on global policy, Oxford University Press.

Britto, P.R., Lye, S.J., Proulx, K., Yousafzai, A.K., Matthews, S.G., Vaivada, T. et al., 2017 'Nurturing care: promoting early childhood development', The Lancet 389(10064), 91-102. https://doi.org/10.1016/S0140-6736(16)31390-3

Bronfenbrenner, U., 1994, 'Ecological models of human development', Internationa Encyclopedia of Education 3(2), 37-43.

Burrell, L., Mcfarlane, E., Tandon, D., Fuddy, L., Duggan, A. \& Leaf, P., 2009, 'Home visitor relationship security: Association with perceptions of work, satisfaction, and turnover', Journal of Human Behavior in the Social Environment 19(5), 592-610. https://doi.org/10.1080/10911350902929005

Center on the Developing Child, 2007, A science-based framework for early childhood policy, Centre on the Developing Child, Harvard University, Cambridge.

Cluver, L., Orkin, M., Boyes, M.E. \& Sherr, L., 2015, 'Child and adolescent suicide attempts, suicidal behavior, and adverse childhood experiences in South Africa: A prospective study', Journal of Adolescent Health 57(1), 52-59. https://doi. org/10.1016/j.jadohealth.2015.03.001

Collins, D., Jordan, C. \& Coleman, H., 2010, An introduction to family social work, 3rd edn., Brooks, Pacific Grove, CA

Cooper, P.J., Tomlinson, M., Swartz, L., Landman, M., Molteno, C., Stein, A. et al., 2009, 'Improving quality of mother-infant relationship and infant attachment in socioeconomically deprived community in South Africa: Randomised controlled trial', British Medical Journal 338, b974. https://doi.org/10.1136/bmj.b974

Coulton, C.J., Korbin, J.E., Su, M. \& Chow, J., 1995, 'Community level factors and child maltreatment rates', Child Development 66(5), 1262-1276. https://doi. org/10.2307/1131646

Dawes, A., Kropiwnicki, Z.D. \& Richter, Z.K., 2005, Corporal Punishment of children: A South African national survey, HSRC press, Cape Town.

Department of Basic Education, 2015, National Curriculum Framework for children from birth to four, Government Printers, Pretoria.

Dhlamini, L., 2016, 'Integrating agenda for 2030 sustainable development goals into regional and national development plans and strategies', in W. Sekwati (ed.), Ideas that work: The South African public sector Innovation Journal 7(1), 12-16.

Dlamini, B.O., 2015, In: National Integrated Early Childhood Development Policy, Government Printers, Pretoria.

Dwyer, S., 2012, 'Walking the tightrope of a mental health act assessment', Journal of Socia Work Practice 26(3), 341-353. https://doi.org/10.1080/02650533.2011.629293

Ebrahim, H., Hasina, B., Killian, B. \& Rule, P., 2011, 'Practices of early childhood development practitioners for poor and vulnerable children from birth to four years in South Africa', Early Child Development and Care 181(3), 387-3396. https://doi.org/10.1080/03004430903392602

Ebrahim, H., Seleti, J. \& Dawes, A., 2013, Learning begins at birth: Improving access to early learning, South African Child Gauge, Children's Institute, University of Cape Town, Cape Town, viewed 04 March 2019, from http://www.ci.uct.ac.za/ sites/default/files/image_tool/images/367/Child_Gauge/South_African_Child_ Gauge_2013/Gauge2013EarlyLearning.pdf.
Etikan, I., Musa, S.A. \& Alkassim, R.S., 2016, 'Comparison of convenience sampling and purposive sampling', American Journal of Theoretical and Applied Statistics 5(1), 1-4. https://doi.org/10.11648/j.ajtas.20160501.11

Fang, X., Zheng, X., Fry, D.A., Ganz, G., Casey, T., Hsiao, C. et al., 2017, 'The economic burden of violence against children in South Africa', International Journal of Environmental Research and Public Health 14(11), 1431. https://doi.org/10.3390/ ijerph14111431

Finifter, D.H., Jensen, C.J., Wilson, C.E. \& Koenig, B.L., 2005, 'A comprehensive, multitiered, targeted community needs assessment model: Methodology, dissemination, and implementation', Family \& Community Health 28(4), 293-306. $\mathrm{https} / / /$ doi.org/10.1097/00003727-200510000-00003

Garthwait, C.L., 2008, The social work practicum: a guide and work book for students, Allyn and Bacon, Boston, MA.

Gill, S., Greenberg, M.T., Moon, C. \& Margraf, P., 2007, 'Home visitor competence, burnout, support, and client engagement', Journal of Human Behavior in the Social Environment 15(1), 23-44. https://doi.org/10.1300/J137v15n01_02

Gomby, D.S., Culross, P.L. \& Behrman, R.E., 1999, 'Home visiting: Recent program evaluations: Analysis and recommendations', The Future of Children 9(1), 4-26. https://doi.org/10.2307/1602719

Govender, B., 2015, 'The development of guidelines for social workers involved in early childhood development within the Department of Social Development', PhD thesis, University of the Western Cape, Cape Town.

Grantham-McGregor, S., Cheung, Y.N., Cueto, S., Glewwe, P., Richter, L. \& Strupp, B., 2007, 'Developmental potential in the first 5 years for children in developing countries', The Lancet 369, 60-70. https://doi.org/10.1016/S01406736(07)60032-4

Grobler, H.D., Schenk, C.J. \& Mbedzi, R.P., 2013, Person-centred facilitation: Process, theory and practice, Oxford University Press Southern Africa, Cape Town.

Gwele, M. \& Ebrahim, S.B., 2019, 'Challenges in implementing a home visiting model for early childhood development in South Africa', in H.B. Ebrahim, A. Okwany \& O. Barry (eds.), Early childhood care and education at the margins: African perspectives on birth to three, Routledge, London.

Hall, K., Sambu, W., Berry, L., Giese, S. \& Almeleh, C., 2017, South African Early Childhood Review 2017, Children's Institute, University of Cape Town, Cape Town.

Harden, B.J., Denmark, N. \& Saul, D., 2010, 'Understanding the needs of staff in Head Start programs: The characteristics, perceptions, and experiences of home visitors', Children and Youth Services Review 32(3), 371-379. https://doi org/10.1016/j.childyouth.2009.10.008

Hombrados-Mendieta, I. \& Cosano-Rivas, F., 2013, 'Burnout, workplace support, job satisfaction and life satisfaction among social workers in Spain: A structural equation model', International Social Work 56(2), 228-246. https://doi. org/10.1177/0020872811421620

Krueger, R.A. \& Casey, M.A., 2014, Focus groups: A practical guide for applied research, Asia-Pacific, Singapore.

Le Roux, I., Le Roux, K., Comulada, W.C., Greco, E.M., Desmond, K.A., Mbewu, N. et al. 2010, 'Home visits by neighborhood mentor mothers provide timely recovery from childhood malnutrition in South Africa: Results from a randomized controlled from childhood malnutrition in South Africa: Results from a randomized controll
trial', Nutrition Journal 9(56), 1-10, https://doi.org/10.1186/1475-2891-9-5

Lee, E., Esaki, N., Kim, J., Greene, R., Kirkland, K. \& Mitchell-Herzfeld, S., 2013, 'Organizational climate and burnout among home visitors: Testing mediating effects of empowerment', Children and Youth Services Review 35(4), 594-602. https://doi.org/10.1016/j.childyouth.2013.01.011

Leeuw, S., 2017, Informal interview for local newspaper by director of Child Welfare East London, East London, South Africa.

Lipshitz, S.J. 2012, 'The educational and psychological role that grandparents play when raising vulnerable learners', Unpublished master's dissertation, University of Johannesburg, Johannesburg, South Africa.

Martin, P., 2015, Analysis of the children's sector in South Africa, Save the Children South Africa, Pretoria.

Massyn, N., Peer, N., English, R., Padarath, A., Barron, P. \&, Day, C. (eds.), 2016, District Health Barometer 2015/16, Health Systems Trust, Durban.

Mathews, S., Abrahams, N., Jewkes, R., Martin, L.J. \& Lombard, C., 2012, Child homicide patterns in South Africa: Is there a link to child abuse?, Research brief, South African Research Council-August.

Mathews, S. \& Gould, C., 2017, 'Preventing violence: From evidence to implementation', ChildGauge, 2017 61-67, viewed 06 August 2019, from https:// www.unicef.org/esa/sites/unicef.org.esa/files/2018-09/UNICEF-South-Africa2017-Child-Gauge.pdf\#page $=63$

Miedel, W.T. \& Reynolds, A.J., 1999, 'Parental involvement in early development for disadvantaged children: Does it matter?', Journal of School Psychology 37(4), 379-402. https://doi.org/10.1016/\$0022-4405(99)00023-0

Morgan, B., 2013, 'Biological embedding of early childhood adversity: Toxic stress and the vicious cycle of poverty in South Africa', Research and Policy Brief Series 2 1-11.

Moshabela, M., Sips, I. \& Barten, F., 2015, 'Needs assessment for home-based care and the strengthening of social support networks: The role of community care workers in rural South Africa', Global Health Action 8(1), 29265. https://doi org/10.3402/gha.v8.29265

Motshekga, A.M., 2015, The South African national curriculum framework for children from birth to four, Department of Basic Education, Pretoria.

Mouton, S. \& Marais, H.C., 1994, Basic concepts in the methodology of the social sciences, HSRC Press, Pretoria, South Africa. https://doi.org/10.1375/ ajgc.17.1.8 
Mulder, E.J., De Medina, P.R., Huizink, A.C., Van Den Bergh, B.R., Buitelaar, J.K. \& Visser, G.H., 2002, 'Prenatal maternal stress: Effects on pregnancy and the (unborn) child', Early Human Development 70(1-2), 3-14. https://doi.org/10.1016/S03783782(02)00075-0

Narsee, A.J., 2013, Children betrayed: A shortage of social workers betrays children viewed 06 July 2018, from http://www.mediamonitoringafrica.org/images/ uploads/The_Times_03062013_p12.JPG

National Planning Commission, 2015, The national development plan 2030, Republic of South Africa, viewed 06 July 2018, from https://nationalplanningcommission. wordpress.com/the-national-development-plan.

Petersen, I., Swartz, L., Bhana, A. \& Flisher, A.J., 2010, 'Mental health promotion initiatives for children and youth in context of poverty: The case of South Africa' Health Promotion International 25(3), 331-341. https://doi.org/10.1093/heapro/ daq026

Phillips, D.A. \& Shonkoff, J.P. (eds.), 2000, From neurons to neighborhoods: The science of early childhood development, National Academies Press, Washington, DC

Pope, N.D. \& Hadden, J.B., 2011, 'Tips for making home visits in Child Welfare', The New Social Worker: The Social Work Careers Magazine, viewed 06 July 2018, from http://www.socialworker.com/feature-articles/practice/Tips_for_Making Home_Visits_in_Child_Welfare/.

Republic of South Africa, 2015, National Integrated Early Childhood Development Policy, Government Printers, Pretoria.

Reynolds, A.J., 1998, 'Developing early childhood programmes for children and families at risk: Research-based principles to promote long-term effectiveness', Children and Youth Service Review 20(6), 503-523.

Richter, L.M., 1999, 'Parenting in poverty: Young children and their families in South Africa', in L. Eldering \& P.M. Leseman (eds.), Effective early education: Crosscultural perspectives, pp. 191-211, Falmer Press, New York.

Richter, L.M., 2003, 'Poverty, underdevelopment and infant mental health', Journa of Paediatrics and Child Health 39, 243-248. https://doi.org/10.1046/j.1440 1754.2003.00145.x

Roggman, L.A., Cook, G.A., Peterson, C.A. \& Raikes, H.H., 2008, 'Who drops out of early head start home visiting programs?', Early Education and Development 19(4), 574-599. https://doi.org/10.1080/10409280701681870

Schmidt, K., Rala., N., Matengu, M. \& Ruiters, K., n.d., 'Poverty and vulnerable children', in A. Moodley, N. Sotuku, K. Schmidt \& N. Phatudi (eds.), A transdisciplinary approach to early childhood care and education, Oxford, Cape Town.

Schmidt, K. \& Rautenbach, J.V., 2016, 'Field instruction: Is the heart of social work education still beating in the Eastern Cape?', Social Work/Maatskaplike werk 52(4), 589-610. https://doi.org/10.15270/52-4-532
Schorr, L. \& Farrow, F., 2014, 'An evidence framework to improve results', in Harold Richman Public Policy Symposium, Centre for the Study of Social Policy, November, 2014, Washington, DC.

Shonkoff, J.P., Garner, A.S., Committee on Psychosocial Aspects of Child and Family Health \& Committee on Early Childhood, Adoption, and Dependent Care, Section on Developmental and Behavioral Pediatrics, 2012, 'The lifelong effects of early childhood adversity and toxic stress', Pediatrics 129(1), 232-246. https://doi. org/10.1542/peds.2011-2663

Slack, K.S., Holl, J.L., McDaniel, M., Yoo, J. \& Bolgerr, K., 2004, 'Understanding the risks of child neglect: An exploration of poverty and parenting characteristics', Child Maltreatment 9(4), 395-408. https://doi.org/10.1177/1077559504269193

Statistics South Africa, 2016, Mid year population estimates, viewed 06 August 2019, from https://www.statssa.gov.za/publications/P0302/P03022016.pdf.

Statistics South Africa, 2017, South Africa demographic and health survey 2016 Key Indicator Report, viewed 30 August 2018, from https://www.statssa.gov.za/ publications/Report\%2003-00-09/Report\%2003-00-092016.pdf.

UNICEF, 2007, Statistical data on the status of children aged 0-4 in South Africa, viewed 22 June 2017, from https://www.unicef.org/southafrica/SAF_resources_ younglives.pdf.

UNICEF, 2011, South Africa's children: A review of equity and child rights, UNICEF South Africa, Pretoria.

Van Niekerk, L., Ashley-Cooper, M. \& Atmore, E., 2017, Effective early childhood development programme options meeting the needs of young South African children, Centre for Early Childhood Development, Cape Town, viewed 06 July 2018 , from http://www.cecd.org.za/CECD\%20Research\%20Report\%20Low-res.pdf.

Victora, C.G., Adair, L., Fall, C., Hallal, P.C., Martorell, R., Richter, L. et al., 2008, 'Maternal and child undernutrition: Consequences for adult health and human capital', The Lancet 371(9609), 340-357. https://doi.org/10.1016/S0140-6736(07)61692-4

Vorster, A., Sacks, A., Amod, Z., Seabi, J. \& Kern, A., 2016, 'The everyday experiences of early childhood caregivers: Challenges in an under-resourced community', South African Journal of Childhood Education 6(1), 1-9. https://doi.org/10.4102/sajce. v6i1.257

Wagner, M., Spiker, D., Inman Linn, M. \& Hernandez, F., 2003, 'Dimensions of parental engagement in home visiting programs: Exploratory study', Topics in Early Childhood Special Education 23(4), 171-187. https://doi.org/10.1177/02711214 030230040101

Waters, M., 2013, SA has a $77 \%$ social worker shortage, viewed 06 July 2018, from http://www.politicsweb.co.za/party/sa-has-a-77-social-worker-shortage--mikewaters.

Weigel, D.J. \& Martin, S.S., 2006, 'Identifying key early literacy and school readiness issues: Exploring a strategy for assessing community needs', Early Childhood Research \& Practice 8(2), 2 